\title{
Employing a generic dietary multivitamin-mineral supplement to estimate intake in a population of pregnant women
}

\author{
H. Clark ${ }^{1}$, D. Miller ${ }^{2}$, G. Devereux ${ }^{2}$ and J. Kyle ${ }^{1}$ \\ ${ }^{1}$ Public Health Nutrition, University of Aberdeen, Aberdeen, AB25 2ZD and ${ }^{2}$ Department of Child Health, Royal \\ Aberdeen Children's Hospital, Aberdeen AB25 2ZL
}

It is estimated that $33 \%$ of the UK adult population regularly use dietary supplements ${ }^{(1)}$. When estimating nutrient intake in a population this additional source of vitamins and minerals can substantially increase consumption ${ }^{(2)}$. A major challenge of estimating nutrient intake from dietary supplements is incomplete brand information supplied by study participants to allow exact identification of the supplement. To avoid underestimation of intake caused by missing data, previous studies have used a generic supplement generated for the population under investigation ${ }^{(3)}$. The aim of this work is to investigate the effect of applying a generic pregnancy multivitamin-mineral supplement (MVMS) to estimate the nutrient intake of pregnant women reporting taking a MVMS compared to intake calculated using reported branded supplements.

Data was collected from 152 pregnant women participating in a study assessing Vitamin D and E intake. Dietary and supplement information was collected using the Scottish Collaborative Group's FFQ (v6.6) ${ }^{(4)}$. A 'generic' MVMS was created using the weighted average of the nutrient composition of reported supplements. Supplement intakes were then calculated using both the reported brand, and the generic supplement nutrient compositions. The calculated nutrient intakes for each method were then compared using the Wilcoxon signed-rank test.

Ninety two women reported taking a MVMS designed for use in pregnancy. A core set of 14 nutrients were included in the majority of branded supplements (Vitamins D, E, C, B $, \mathrm{B}_{2}, \mathrm{~B}_{3}, \mathrm{~B}_{6}, \mathrm{~B}_{12}$, folic acid, Fe, $\mathrm{Mg}, \mathrm{Zn}$, pantothenoic acid and biotin); the other 5 nutrients (Vitamin $\mathrm{K}, \mathrm{Se}, \mathrm{I}, \mathrm{Cu}$ and $\mathrm{Ca}$ ) were less frequently included. Median intakes calculated by the specific and generic methods were found to be significantly different for vitamins $\mathrm{D}, \mathrm{E}, \mathrm{C}, \mathrm{B}_{2}, \mathrm{~B}_{3}$ and $\mathrm{K}$, Se, I, pantothenoic acid, biotin, $\mathrm{Cu}$ and $\mathrm{Ca}(p<0 \cdot 05)$, but not for the remaining nutrients $(p>0 \cdot 05$, table 1$)$.

Table 1. Comparison of branded and generic supplement intakes

\begin{tabular}{|c|c|c|c|c|c|c|}
\hline \multirow[b]{2}{*}{ Nutrient } & \multirow[b]{2}{*}{ No. of women* } & \multicolumn{2}{|c|}{ Branded supplement } & \multicolumn{2}{|c|}{ Generic supplement } & \multirow[b]{2}{*}{$p$} \\
\hline & & Median & IQR & Median & IQR & \\
\hline Vitamin $B_{1}(\mathrm{mg})$ & 94 & 3.00 & 1.40 & $2 \cdot 62$ & $0 \cdot 00$ & 0.92 \\
\hline Vitamin $B_{6}(\mathrm{mg})$ & 94 & $10 \cdot 00$ & $7 \cdot 40$ & $7 \cdot 56$ & $0 \cdot 00$ & 0.78 \\
\hline Folic acid $(\mu \mathrm{g})$ & 94 & $400 \cdot 00$ & $0 \cdot 00$ & $400 \cdot 00$ & $0 \cdot 00$ & 1.00 \\
\hline Vitamin $B_{12}(\mu \mathrm{g})$ & 94 & $6 \cdot 00$ & $3 \cdot 50$ & $5 \cdot 04$ & $0 \cdot 00$ & $0 \cdot 84$ \\
\hline Iron $(\mathrm{mg})$ & 94 & $17 \cdot 00$ & $3 \cdot 00$ & $16 \cdot 02$ & $0 \cdot 00$ & 0.79 \\
\hline Magnesium (mg) & 94 & $150 \cdot 00$ & $50 \cdot 00$ & $133 \cdot 80$ & $0 \cdot 00$ & $0 \cdot 55$ \\
\hline Zinc (mg) & 94 & $15 \cdot 00$ & $5 \cdot 36$ & $12 \cdot 85$ & $0 \cdot 00$ & $0 \cdot 80$ \\
\hline
\end{tabular}

* No. of women taking nutrient from branded supplement.

In conclusion, employing a generic supplement to estimate nutrient intake from supplements should be used with caution as it may not produce a reliable estimate of intake.

1. Bates B, Lennox A, Swan G (2010) The National Diet and Nutrition Survey: Headline Results From Year 1 of the Rolling Programme (2008/2009). London, UK: Food Standards Agency.

2. Haugen M, Brantsæter AL, Alexander J, Meltzer HM (2008) Ann Nutr Metab 52, 272-280

3. Lentjes MAH, Bhaniani A, Mulligan AA, Khaw K, Welch AW (2010) Public Health Nutr 14, 459-471

4. http://www.foodfrequency.org/ 